\title{
Maintenance therapy in COPD: time to phase out ICS and switch to the new LAMA/LABA inhalers?
}

\author{
This article was published in the following Dove Press journal: \\ International Journal of COPD \\ 23 June 2017 \\ Number of times this article has been viewed
}

\author{
Syed Mohammad Tariq' \\ Enson C Thomas ${ }^{2}$ \\ 'Department of Respiratory Medicine, \\ Luton and Dunstable University \\ Hospital, Luton, ${ }^{2}$ Respiratory Unit, \\ Bedford Hospital, Bedford, UK
}

\begin{abstract}
Long-term maintenance therapy for COPD is evolving rapidly. Dual bronchodilation with new long-acting muscarinic antagonist and long-acting beta-agonist (LAMA/LABA) fixed dose combination inhalers were introduced over the past 2 years. In clinical trials, these inhalers significantly improved lung function (trough forced expiratory volume in 1 second), patient-reported outcomes, and quality of life measures compared with placebo, their respective monocomponents, and tiotropium. The recorded adverse events of these new inhalers were also similar to those of their monocomponents or placebo. There are concerns regarding long-term complications (weight gain, osteoporosis, cataract) and increased risk of community-acquired pneumonia with the use of inhaled corticosteroids (ICS). The new LAMA/LABA inhalers could potentially reduce the use of ICS as part and parcel of maintenance therapy in COPD. Recent studies compared these LAMA/LABA inhalers with ICS/LABA combination inhalers in moderate-to-severe COPD. The results are promising and favor the LAMA/LABA inhalers, especially in the longer duration trials. Furthermore, there is a clearer picture emerging as to the subgroup of COPD patients who may be able to successfully switch from their current ICS/LABA therapy to these new LAMA/LABA inhalers.
\end{abstract}

Keywords: COPD, dual bronchodilation, exacerbations, inhaled corticosteroid, long-acting beta-agonist, long-acting muscarinic antagonist

\section{Introduction}

The UK National Institute of Clinical and Healthcare Excellence (NICE) guidelines promoted the use of inhaled corticosteroid/long-acting beta agonist (ICS/LABA) inhalers in COPD. ${ }^{1}$ However, long-term ICS use can cause a host of side effects. Some may be considered cosmetic or trivial, such as skin thinning and bruising, and redistribution of body fat, whereas others carry significant morbidity (weight gain, pneumonia, osteoporosis leading to fractures). Considering these side effects, and the fact that there are no proven gains in non-exacerbators, we should avoid prescribing ICS to this subgroup of COPD patients. ${ }^{2}$

In the past 2 years, dual bronchodilation with new long-acting muscarinic antagonist (LAMA)/LABA inhalers have become available. Current NICE COPD guidelines were published in 2010. ${ }^{1}$ Hence, they do not cover these new inhalers. However, global initiative for chronic obstructive lung disease (GOLD), recently, updated their guidelines and placed dual bronchodilation earlier than ICS in the stepwise escalation of therapy based on symptoms (COPD assessment tool score) and rates of exacerbations. ${ }^{3}$ This is a major shift, as older guidelines linked maintenance therapy to stable-state forced expiratory volume in 1 second $\left(\mathrm{FEV}_{1}\right)$. However, this shift is warranted as lung function often does not match severity of symptoms, functional limitation, and exacerbation rates. ${ }^{4}$
Correspondence: Syed Mohammad Tariq Department of Respiratory Medicine, Luton and Dunstable University Hospital, Lewsey Road, Luton LU4 ODZ, UK

Tel +4478 86025415

Fax +44 I5 82497237

Email syed.tariq@Idh.nhs.uk
International Journal of COPD 2017:12 I877-1882

(c) (1) (8) ( 2017 Tariq and Thomas. This work is published and licensed by Dove Medical Press Limited. The full terms of this license are available at https.//mww.dovepress.com/terms.php cc. hereby accept the Terms. Non-commercial uses of the work are permitted without any further permisision from Dove Medical Press Limited, provided the work is properly attributed. For permission

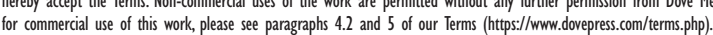


In controlled trials, the new LAMA/LABA inhalers show clinical and statistically significant efficacy regarding lung function, patient-reported outcome, and health-related quality of life gains in moderate-to-severe COPD versus placebo, tiotropium, and monotherapy with their constituents. ${ }^{5-11}$ The gains in $\mathrm{FEV}_{1}$ with these new inhalers are comparable, and their side effect profile is similar to treatment with their monocomponents, tiotropium, or placebo. But can they replace ICS/LABA inhalers? In this review, based on evidence from comparative studies of dual bronchodilation inhalers versus ICS/LABA, we suggest a number of changes to COPD maintenance therapy.

\section{Trials of the new LAMA/LABA inhalers versus ICS/LABA therapy}

There are four LAMA/LABA fixed dose combination (FDC) inhalers available now. Apart from tiotropium + olodaterol, all others are dry powder inhalers:

1. Umeclidinium $62.5 \mu \mathrm{g}+$ vilanterol $25 \mu \mathrm{g}$ (GlaxoSmithKlein, Brentford, Middlesex, UK).

2. Indacaterol $85 \mu \mathrm{g}+$ glycopyrronium $43 \mu \mathrm{g}$ (Pfizer, New York, NY, USA).

3. Tiotropium $2.5 \mu \mathrm{g}+$ olodaterol $2.5 \mu \mathrm{g}$ (Boehringer Ingelheim, Ingelheim am Rhein, Germany).

4. Aclidinium $340 \mu \mathrm{g}+$ formoterol $12 \mu \mathrm{g}$ (AstraZeneca, London, UK).

One of the components in the third and fourth LAMA/ LABA FDCs, listed above, is a well-established agent with several years of clinical use (tiotropium and formoterol, respectively).

Recent studies have compared these inhalers with ICS/ LABA inhalers, which are currently in use. Umeclidinium/ vilanterol taken once daily significantly improved the mean 24-hour $\mathrm{FEV}_{1}$ on day 84 of treatment, and pre-dose $\mathrm{FEV}_{1}$ compared with fluticasone/salmeterol 500/50 $\mu \mathrm{g}$ twice daily. ${ }^{12}$ However, gains in transitional dyspnea index (TDI) and St Georges Respiratory Questionnaire (SGRQ) score were similar in the two treatment groups.

In the LANTERN study, pre-dose $\mathrm{FEV}_{1}$ was better at day 1, week 12 and week 26 in patients receiving indacaterol/ glycopyrronium inhaler once daily compared with patients on fluticasone/salmeterol 500/50 $\mu \mathrm{g}$ twice daily. ${ }^{13}$ Again there was no difference in improvements in TDI and SGRQ between the treatment groups. Annualized exacerbation rates, however, were significantly lower $(0.31$ versus 0.45 ; $P=0.048$ ) in the indacaterol/glycopyrronium treated group, and rates of pneumonia $(2.7 \%$ versus $0.8 \%)$ and upper respiratory infection ( $7 \%$ versus $3.5 \%$ ) were significantly higher in the fluticasone/salmeterol group.
The FLAME study compared once daily indacaterol/ glycopyrronium with twice daily fluticasone/salmeterol $500 / 50 \mu \mathrm{g}$ for a longer treatment duration of 1 year. ${ }^{14}$ The indacaterol/glycopyrronium treated group had $11 \%$ fewer exacerbations $(P=0.003)$ than the fluticasone/salmeterol treated group and the average time to first exacerbation was also significantly longer (71 versus 51 days; $P<0.001$ ). As expected, there were more cases of pneumonia in the fluticasone/salmeterol arm (4.8\% versus 3.2\%). This longer duration study also showed significant improvement in SGRQ scores in those taking indacaterol/glycopyrronium versus those on the fluticasone/salmeterol inhaler.

Aclidinium/formoterol taken twice daily, was compared with twice daily fluticasone/salmeterol $500 / 50 \mu \mathrm{g}$ in a 24-week Phase III trial. ${ }^{15}$ Aclidinium/formoterol increased the trough $\mathrm{FEV}_{1}$ significantly more than fluticasone/salmeterol. Exacerbation rates and improvements in TDI were similar in the two treatment groups, whereas pneumonia $(1.9 \%$ versus $0.6 \%)$ and rates of adverse events after excluding exacerbations were higher in the fluticasone/ salmeterol group.

Two doses of once daily inhaled tiotropium/olodaterol (5/5 and $2.5 / 5 \mu \mathrm{g}$ ) were compared with two doses of salmeterol/ fluticasone $(50 / 500$ and 50/250 $\mu \mathrm{g})$ over a 6-week treatment period. ${ }^{16}$ There was a statistically significant improvement in 0-12 hour $\mathrm{FEV}_{1}$ area under the curve (AUC) in the tiotropium/ olodaterol groups compared with the salmeterol/fluticasone groups. The gains were of the order of $30 \%-40 \%\left(\mathrm{FEV}_{1}\right.$ $\mathrm{AUC}_{0-12}$ for tiotropium/olodaterol 5/5 and 2.5/5 $\mu \mathrm{g}=317$ and $295 \mathrm{~mL}$ versus $\mathrm{FEV}_{1} \mathrm{AUC}_{0-12}$ for salmeterol/fluticasone $50 / 500$ and $50 / 250 \mu \mathrm{g}=188$ and $192 \mathrm{~mL}$, respectively). All treatments were well tolerated. The study period, however, was too short to detect significant differences in patient reported outcomes or rates of pneumonia.

\section{Can we wean COPD patients from ICS to the new LAMA/LABA FDCs?}

Given the significant adverse effects and increased incidence of pneumonia with long-term use of ICS, a favorable efficacy and safety profile of new LAMA/LABA FDCs versus ICS/LABA in COPD patients is very encouraging. However, can we safely wean our COPD patients off ICS and leave them on these new inhalers, without jeopardizing disease control or risking exacerbations?. The answer to this key question was provided, recently, by the Withdrawal of Inhaled Steroids during Optimized Bronchodilator Management (WISDOM) study. ${ }^{17}$ In a large cohort of severe-to-very severe COPD patients, the researchers successfully withdrew 
ICS (fluticasone) with no clinically significant deterioration in patient-reported outcomes, nor a statistically significant rise in exacerbation rates. ${ }^{17}$ As per study protocol, patients weaned off ICS were maintained on inhaled LAMA and LABA, whereas the control group continued triple therapy. Mean trough $\mathrm{FEV}_{1}$ was marginally lowered after 18 weeks $(-38 \mathrm{~mL}, P<0.001)$ and 1 year $(-43 \mathrm{~mL}, P=0.001)$ of treatment in the study group compared with controls. Differences between groups in dyspnea index (modified Medical Research Council [mMRC] dyspnea scale) and health-related quality of life (SGRQ) were small and clinically insignificant.

\section{Potential role of blood eosinophil count in predicting a response to ICS}

A post hoc analysis of the WISDOM study suggested that long-term ICS treatment may reduce the rate of exacerbations in a minority of moderate-to-severe COPD patients with blood eosinophil counts of $>300$ cells $/ \mu \mathrm{L}$ (or $>4 \%$ of total white cell count). ${ }^{18}$ In a separate post hoc analysis of two large multinational studies comparing treatment with inhaled once daily fluticasone furoate/vilanterol to once daily vilanterol, Hinds et al found that patients with eosinophil count $>2.4 \%$, generally, responded better to fluticasone furoate/vilanterol. ${ }^{19}$ However, there was an additional influence of tobacco smoking on the outcomes. The inference from their analysis was that, in general, low eosinophil counts $(\leq 2.4 \%)$ coupled with high levels of smoking ( $>46$ pack years) could predict a poor response to ICS, with no significant reduction in exacerbation rates. Whether these cut-offs of blood eosinophilia among the frequent exacerbators are reliable markers of ICS responsiveness, needs confirmation. Interestingly, the FLAME study found reduced exacerbation rates in the indacaterol-/glycopyrronium-treated patients compared with fluticasone-/salmeterol-treated group irrespective of their blood eosinophil counts. ${ }^{14}$

\section{Cost impact assumptions of the new LAMA/LABA FDCs}

The cost of 1-month treatment with these new inhalers in UK primary care is comparable:

1. Umeclidinium/vilanterol

2. Tiotropium/olodaterol

3. Aclidinium/formoterol

4. Indacaterol/glycopyrronium

$£ 32.50$

A month's treatment with branded combinations of fluticasone/salmeterol 500/50 $\mu \mathrm{g}$ (GlaxoSmithKline) and budesonide/formoterol 400/12 $\mu \mathrm{g}$ (AstraZeneca) dry powder inhalers is more expensive than the new LAMA/LABA FDCs ( $£ 40.80$ for fluticasone/salmeterol and $£ 38.00$ for budesonide/formoterol). However, a month's treatment with beclomethasone/formoterol 100/6 $\mu \mathrm{g}$ pressurized metered dose inhaler (Chiesi Limited, Manchester, UK), two puffs twice daily, or the generic fluticasone/salmeterol 500/50 $\mu \mathrm{g}$ inhaler, would cost marginally less at $£ 29.32$ and $£ 29.97$, respectively.

Price et al estimated that over $26 \%$ of COPD patients (after excluding those with coexisting asthma) in the UK primary care setting are on ICS/LABA alone. ${ }^{2}$ This subgroup seems ideal for a switch to dual bronchodilation with LAMA/LABA FDCs. Based on the estimates of Price et al, we expect approximately 730 COPD patients managed by the Luton Clinical Commissioning Group (CCG) and 1,900 COPD patients managed by the Bedford CCG are on ICS/ LABA alone (Luton and Bedford CCG patient lists, 2016). A majority of these patients are likely to be non-exacerbators or those with blood eosinophil counts $<300$ cells $/ \mu L$. Clearly, ongoing ICS treatment could significantly harm these patients without providing any potential benefit. Hence, they should be switched from ICS/LABA to LAMA/LABA inhalers. Extrapolating from the results of two published comparative studies of indacaterol/glycopyrronium versus fluticasone/ salmeterol, namely the LANTERN ${ }^{13}$ and FLAME ${ }^{14}$ trials, we estimate that weaning this subgroup off ICS/LABA to the indacaterol/glycopyrronium FDC in the Bedford and Luton CCG areas $(n=2630)$ could potentially reduce the rates of moderate-to-severe exacerbations by $\sim 150$ per annum. Switching this subgroup to an LAMA/LABA competitor of indacaterol/glycopyrronium FDC, namely, umeclidinium/ vilanterol, tiotropium/olodaterol, and aclidinium/formoterol, could potentially yield similar gains. However, we do not yet have comparative data on exacerbation rates from long-term studies for these FDCs.

LAMA/LABA FDCs significantly reduce the risk of pneumonia by 33\%-67\% compared with ICS containing combinations - annualized pneumonia rates for indacaterol/ glycopyrronium versus fluticasone/salmeterol $=0.8 \%$ versus $2.7 \%$ in the LANTERN study, ${ }^{13}$ yearly pneumonia rates for indacaterol/glycopyrronium versus fluticasone/ salmeterol $=3.2 \%$ versus $4.8 \%$ in the FLAME study, ${ }^{14}$ and pneumonias over 24-week treatment with aclidinium/formoterol versus fluticasone $/$ salmeterol $=0.6 \%$ versus $1.9 \% .{ }^{15}$ Hence, the switch from ICS/LABA to LAMA/LABA in the estimated 2,630 COPD patients taking ICS/LABA alone in Bedfordshire, should also lead to 40-70 fewer episodes of pneumonia per year. 
Given the substantial reductions in rates of moderate-tosevere exacerbations and pneumonia per annum, the switch from ICS/LABA to LAMA/LABA FDCs offers substantial cost savings. In addition to this, the avoidance of long-term corticosteroid side effects, a case for such a switch is now very compelling indeed.

\section{Conclusion and recommendations}

In summary, comparative data on trials of the new LAMA/ LABA FDC inhalers against one of the ICS/LABA combination inhalers (fluticasone plus salmeterol) are now available, and the results significantly favor the LAMA/ LABA inhalers in terms of efficacy (improvements in $\mathrm{FEV}_{1}$ ), patient-reported outcomes (TDI, $\mathrm{mMRC}$ ), and quality of life measures (SGRQ). Furthermore, significant reductions in exacerbation rates were also shown in the longer duration trials with some of these dual bronchodilator inhalers. A recently published Cochrane Database Systematic Review of the available combination inhaler therapies for COPD also concluded that "Although risk of serious side effects and death were not affected by the choice of treatment, compared to LABA + ICS, LAMA + LABA was associated with a lower risk of flare-ups, fewer episodes of pneumonia, larger improvement in how well the lungs work, and improved quality of life". ${ }^{20}$

Clearly there are concerns that we are over-using ICS/ LABA as maintenance therapy in COPD leading to significant harm from long-term ICS side effects, and an increased risk of pneumonia. ${ }^{13-15,21}$ However, there is good evidence now, to switch our moderate-to-severe COPD patients from ICS/LABA inhalers to the newer LAMA/LABA inhalers. The current LAMA/LABA FDCs show comparable efficacy and an extremely favorable side effect profile.

Switching patients from ICS/LABA to LAMA/LABA inhalers will be cost-effective in terms of significant reductions in rates of COPD exacerbations and pneumonia. The costs of morbidity due to long-term complications of ICS (fractures resulting from steroid-induced osteoporosis, steroid-induced diabetes, cataract) are more difficult to estimate. Phasing out the use ICS/LABA inhalers in favor of the new LAMA/LABA FDCs in a majority of COPD patients should significantly reduce the incidence of these long-term ICS-related complications as well.

\section{Hence, we recommend}

1. Newly diagnosed COPD patients

- Approve all four LAMA/LABA inhalers as first line in symptomatic moderate-to-severe COPD patients.
- Exacerbators: look at the eosinophil count:

- If eosinophil count $>0.3 \times 10^{9} \mu \mathrm{L}$ - prescribe low dose ICS (eg, beclomethasone $100 \mu \mathrm{g} /$ puff pressurized metered dose inhaler, two puffs twice daily).

- If eosinophil count $<0.3 \times 10^{9} \mu \mathrm{L}$ - rule out bronchiectasis, treat with an LAMA/LABA FDC, and consider long-term antibiotic (azithromycin $250 \mathrm{mg}$ three times a week or doxycycline $100 \mathrm{mg}$ once daily).

- If coexisting bronchiectasis - consider additional measures of regular sputum clearance \pm a mucolytic (carbocisteine).

2. COPD patients, currently, on ICS/LABA

- Exacerbators:

- If eosinophil count $<0.3 \times 10^{9} \mu \mathrm{L}$ - wean off ICS/ LABA and commence an LAMA/LABA. If they continue to have exacerbations, rule out bronchiectasis and consider long-term antibiotic (azithromycin $250 \mathrm{mg}$ three times a week or doxycycline $100 \mathrm{mg}$ once daily).

- If eosinophil count $>0.3 \times 10^{9} \mu \mathrm{L}$ - continue ICS/ LABA and add an LAMA.

- Non-exacerbators:

- Wean off ICS/LABA and commence an LAMA/ LABA inhaler.

- Modify ICS weaning regimen in line with WISDOM study, to suit inhalers containing an ICS other than fluticasone, especially in frequent exacerbators. WISDOM study followed a pragmatic regimen of gradual weaning off fluticasone. ${ }^{17,18}$

- Monitor patients weaned off ICS closely, with frequent reviews at least in the initial 2-3 months, as a small minority may suffer slight worsening of COPD symptoms after discontinuing ICS. ${ }^{17,18}$

These suggestions are broadly in line with the recently updated GOLD guidelines. ${ }^{3}$ The GOLD guidelines recommend starting with LAMA or LABA monotherapy in symptomatic COPD patients, and then stepping up to an LAMA/ LABA FDC if the response is suboptimal. ${ }^{3}$ However, given the better efficacy, equivalent tolerability, and similar costs of LAMA/LABA FDCs compared with their monocomponents, their use as first-line therapy in all newly diagnosed symptomatic COPD patients may be justified.

ICS as monotherapy does not improve lung function to a clinically significant level in COPD. However, when combined with bronchodilator therapy, it does have a role in patients with asthma-COPD overlap syndrome (ACOS). ${ }^{22}$ For the subgroup of frequent exacerbators, we need further 
studies on the value of blood eosinophil count in predicting a response to ICS. In the WISDOM study, a small proportion of exacerbators with eosinophil counts $>300$ cells $/ \mu \mathrm{L}$ suffered more frequent exacerbations after stopping ICS. ${ }^{18}$ Hence, a majority of our moderate-to-severe COPD patients, currently, on long-term ICS/LABA inhalers with or without an LAMA inhaler should be able to come off the ICS and switch successfully to one of the new LAMA/LABA inhalers. Based on the results of the WISDOM study, we have suggested using blood eosinophil count of $>0.3 \times 10^{9} \mu \mathrm{L}$ as a potential indicator of ICS responsiveness in COPD. We acknowledge that robust evidence for it is lacking, but we believe this is a pragmatic approach until the issue of the most reliable marker(s) of ICS responsiveness and their respective cut-off levels is resolved.

Aside from the blood eosinophil count, other potential markers to predict a therapeutic response to ICS in COPD include a stable-state elevated fraction of exhaled nitric oxide (FeNO), and the presence of atopy. A recent study of 200 COPD patients showed that $8 \%$ had an intermediate level FeNO of 25-50 parts per billion (ppb) and 3\% had a high FeNO of $>50 \mathrm{ppb}^{23}$ Interestingly, intermediate and high FeNO levels were more common in patients with features of asthma/COPD overlap. ${ }^{23}$

The European Respiratory Society Study on Chronic Obstructive Pulmonary Disease detected atopy among 18\% of COPD patients. ${ }^{24}$ These patients were more likely to be male, overweight/obese, and younger, and they had a higher prevalence of cough (odds ratio [OR] 1.71) and sputum production (OR 1.50). These symptoms responded well to treatment with inhaled budesonide. ${ }^{24}$ Unfortunately, any impact of ICS therapy on exacerbation rates in this cohort was not reported. FeNO and coexisting atopy, therefore, deserve further evaluation as potential markers for ICS responsiveness in COPD patients.

For frequent exacerbators with eosinophil counts $<300$ cells $/ \mu \mathrm{L}$, treatment with long-term prophylactic antibiotic (azithromycin $250 \mathrm{mg}$ three times weekly, or doxycycline $100 \mathrm{mg}$ daily) in addition to an LAMA/LABA FDC inhaler would be appropriate. ${ }^{25,26}$ However, emergence of resistant bacterial strains remains a significant concern with long-term use of a broad-spectrum antibiotic. ${ }^{27}$

In general, macrolide antibiotics provide adequate coverage for commonly encountered pathogens in acute exacerbations of COPD. ${ }^{28}$ When used as prophylaxis against infective exacerbations in patients with COPD, non-cystic fibrosis bronchiectasis, and diffuse panbronchiolitis, they also exert a wide range of immunomodulatory effects which limit tissue damage by neutrophils. ${ }^{28}$ However, we should exercise due caution and monitor our patients closely, as long-term use of macrolides may cause significant side effects, such as hearing loss and liver toxicity.

Doxycycline as an alternative, may also have potential benefits when used as prophylaxis against infective exacerbations in COPD. It too has significant clinical efficacy against pathogens implicated in COPD exacerbations and possesses a number of anti-inflammatory properties, including suppression of neutrophil migration and inhibition of matrix metalloproteinase enzymes. ${ }^{26}$

Investigating frequent exacerbators for coexisting bronchiectasis is recommended, as they may benefit further from daily sputum clearance exercises and regular treatment with a mucolytic agent such as carbocisteine.

The new LAMA/LABA FDCs are now widely available and are a welcome addition to the options available for maintenance therapy in COPD. However, the doses of the active agents per puff in these inhalers may differ between countries and regions. Hence in some countries the efficacy of the new LAMA/LABA FDCs may not match the results and outcomes of the studies cited in this review.

\section{Acknowledgments}

We thank Azim and Partners, Grovemead Health Centre, 67 Elliot Road, London NW4 3EB, for providing the current monthly treatment costs for ICS/LABA and LAMA/LABA inhalers in the UK primary care.

\section{Disclosure}

The authors report no conflict of interest in this work.

\section{References}

1. National Clinical Guideline Centre 2010. Available from: http://guidance. nice.org.uk/CG101/Guidance/pdf/English. Accessed February 25, 2017.

2. Price D, West D, Brusselle G, et al. Management of COPD in the UK primary-care setting: an analysis of real-life prescribing patterns. Int $J$ Chronic Obstruct Pulmon Dis. 2014;9:889-904.

3. Global Initiative for Chronic Obstructive Lung Disease (GOLD). Global strategy for the diagnosis, management, and prevention of chronic obstructive pulmonary disease. 2017 report. Available from: http://goldcopd. org. Accessed March 18, 2017.

4. Westwood M, Bourbeau J,Jones PW, Cerulli A, Capkun-Niggli G, Worthy G. Relationship between $\mathrm{FEV}_{1}$ change and patient-reported outcomes in randomised trials of inhaled bronchodilators for stable COPD: a systematic review. Respir Res. 2011;12:40.

5. Bateman E, Ferguson GT, Barnes N, et al. Dual bronchodilation with QVA149 vs. single bronchodilator therapy: the SHINE study. Eur Respir J. 2013;42(6):1484-1494

6. Decramer M, Anzueto A, Kerwin E, et al. Efficacy and safety of umeclidinium plus vilanterol versus tiotropium, vilanterol, or umeclidinium monotherapies over 24 weeks in patients with chronic obstructive pulmonary disease: results from two multicentre, blinded, randomised controlled trials. Lancet Respir Med. 2014;2(6):472-486. 
7. Singh D, Jones PW, Bateman ED, et al. Efficacy and safety of aclidinium bromide/formoterol fumarate fixed dose combinations compared with individual components and placebo in patients with COPD (ACLIFORM-COPD): a multicentre, randomised study. BMC Pulm Med. 2014;14:178.

8. Buhl R, Maltais F, Abrahams R, et al. Tiotropium and olodaterol fixed dose combination versus monocomponents in COPD (GOLD 2-4). Eur Respir J. 2015;45(4):969-979.

9. Buhl R, Gessner C, Schuermann W, et al. Efficacy and safety of oncedaily QVA149 compared with the free combination of once-daily tiotropium and twice daily formoterol in patients with moderate-to-severe COPD (QUANTIFY): a randomised non-inferiority study. Thorax. 2015;70(4):311-319.

10. D’Urzo AD, Rennard SI, Kerwin EM, Mergel V, Leselbaum AR, Caracta CF; AUGMENT COPD Study investigators. Efficacy and safety of fixed-dose combinations of aclidinium bromide/formoterol fumarate: the 24-week, randomized, placebo-controlled AUGMENT COPD study. Respir Res. 2014;15:123.

11. Wang L, Zhai CJ, Liu Y, Liu Y, Jiang SJ. Umeclidinium plus vilanterol versus placebo, umeclidinium or vilanterol monotherapies for chronic obstructive pulmonary disease: a meta-analysis of randomized controlled trials. Clin Drug Investig. 2016;36(11):865-875.

12. Donohue JF, Worsley S, Zhu CQ, Hardaker L, Church A. Improvements in lung function with umeclidinium/vilanterol versus fluticasone propionate/salmeterol in patients with moderate-to-severe COPD and infrequent exacerbations. Respir Med. 2015;109(7):870-881.

13. Zhong N, Wang C, Zhou X, et al. LANTERN: a randomized study of QVA149 versus salmeterol/fluticasone combination in patients with COPD. Int J Chron Obstruct Pulmon Dis. 2015;10:1015-1026.

14. Wedzicha JA, Banerji D, Chapman KR, et al. FLAME Investigators. Indacaterol-Glucopyrronium versus Salmeterol-Fluticasone for COPD. N Engl J Med. 2016;374(23):2222-2234.

15. Vogelmeier C, Paggiaro PL, Dorca J, et al. Efficacy and safety of aclidinium/formoterol versus salmeterol/fluticasone: a phase 3 COPD study. Eur Respir J. 2016;48(4):1030-1039.

16. Beeh K-M, Derom E, Echave-Sustaeta J, et al. The lung function

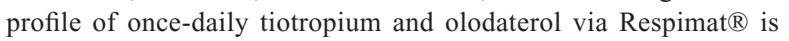
superior to that of twice-daily salmeterol and fluticasone propionate via Accuhaler ${ }^{\circledR}($ ENERGITO $®$ study). Int J Chron Obstruct Pulmon Dis. 2016;11:193-205.
17. Magnussen H, Disse B, Rodriguez-Roison R, et al. WISDOM Investigators. Withdrawal of inhaled glucocorticoids and exacerbations of COPD. N Engl J Med. 2014;371(14):1285-1294.

18. Watz H, Tetzlaff $\mathrm{K}$, Wouters EF, et al. Blood eosinophil count and exacerbations in severe chronic obstructive pulmonary disease after withdrawal of inhaled corticosteroids: a post-hoc analysis of the WISDOM trial. Lancet Respir Med. 2016;4(5):390-398.

19. Hinds DR, DiSantostefano RL, Le HV, Pascoe S. Identification of responders to inhaled corticosteroids in a chronic obstructive pulmonary disease population using cluster analysis. BMJ Open. 2016;6(6):e010099.

20. Horita N, Goto A, Shibata Y, et al. Lg-acting muscarinic antagonist (LAMA) plus lon-acting beta-agonist (LABA) versus LABA plus inhaled corticosteroid (ICS) for stable chronic obstructive pulmonary disease (COPD). Cochrane Database Syst Rev. 2017;2:CD012066.

21. Singh S, Loke YK. Risk of pneumonia associated with long-term use of inhaled corticosteroids in COPD: a critical review and update. Curr Opin Pulm Med. 2010;6(2):118-122.

22. Gillessen A, Haidl P, Kohlhäufl M, Kroegel K, Voshaar T, Gessner C. The pharmacological treatment of chronic obstructive pulmonary disease. Dtsch Arztebl Int. 2016;113(18):311-316.

23. Donohue JF, Herje N, Crater G, Rickard K. Characterization of airway inflammation in patients with COPD using fractional exhaled nitric oxide levels: a pilot study. Int J Chron Obstruct Pulmon Dis. 2014; 9:745-751.

24. Fattahi F, ten Hacken NHT, Löfdahl C-G, et al. Atopy is a risk factor for respiratory symptoms in COPD patients: results from the EUROSCOP study. Respir Res. 2013;14:10.

25. Ni W, Shao X, Cai X, et al. Prophylactic use of macrolide antibiotics for the prevention of chronic obstructive pulmonary disease exacerbation: a meta-analysis. PLoS One. 2015;10(3):e0121257.

26. Dalvi PS, Singh A, Trivedi HR, et al. Effect of doxycycline in patients of moderate to severe chronic obstructive pulmonary disease with stable symptoms. Ann Thor Med. 2011;6(4):221-226.

27. Brill SE, Law M, El-Emir E, et al. Effects of different antibiotic classes on airway bacteria in stable COPD using culture and molecular techniques: a randomised controlled trial. Thorax. 2015;70(10):930-938.

28. Martinez FJ, Curtis JL, Albert R. Role of macrolide therapy in chronic obstructive pulmonary disease. Int J Chron Obstruct Pulmon Dis. 2008;3(3):331-350.
International Journal of COPD

\section{Publish your work in this journal}

The International Journal of COPD is an international, peer-reviewed journal of therapeutics and pharmacology focusing on concise rapid reporting of clinical studies and reviews in COPD. Special focus is given to the pathophysiological processes underlying the disease, intervention programs, patient focused education, and self management protocols.

\section{Dovepress}

This journal is indexed on PubMed Central, MedLine and CAS. The manuscript management system is completely online and includes a very quick and fair peer-review system, which is all easy to use. Visit http://www.dovepress.com/testimonials.php to read real quotes from published authors. 